\title{
DESENVOLVIMENTO E CARACTERIZAÇÃO DE IOGURTE DE MANGABA CONVENCIONAL E DIET
}

Taysa Martins de Oliveira', Ellen Godinho Pinto', Fernando Luiz de Oliveira', Dayana Silva Batista Soares'.

1'Instituto Federal Goiano-Campus Morrinhos, GO. E-mail: ellen.godinho@ifgoiano.edu.br

\section{RESUMO}

O consumo do iogurte está relacionado à imagem positiva de alimento saudável e nutritivo, por ser fonte de proteínas, cálcio, fósforo e vitaminas. A mangaba vem sendo bastante explorada devido seu potencial nutricional e para fabricação de diversos alimentos. O presente trabalho objetivou o desenvolvimento do iogurte de mangaba convencional e diet para estudar as características físicas e química. Pode-se observar que os teores de $\mathrm{pH}$, vitamina $\mathrm{C}$ e densidade, não teve diferença significativa, entre os iogurte de mangaba convencional e diet. Os compostos fenólicos encontrados nos iogurtes foram inferiores a $1 \%$ do encontrado na polpa in natura.

Palavras-chave: compostos fenólicos; teste SNK; vitamina C

\section{DEVELOPMENT AND CHARACTERIZATION OF CONVENTIONAL MANGABA AND DIET YOGHURT}

\begin{abstract}
The consumption of yogurt is related to the positive image of healthy and nutritious food, being a source of protein, calcium, phosphorus and vitamins. Mangrove has been widely exploited because of its nutritional potential and the manufacture of various foods. This work aimed at the development of conventional mangaba yogurt and diet to study their physical and chemical characteristics. It can be observed that the levels of $\mathrm{pH}$, vitamin $\mathrm{C}$ and density had no significant difference between conventional and dietary mango yogurt. The phenolic compounds found in yogurt were less than $1 \%$ of that found in fresh pulp.
\end{abstract}

Keywords: phenolics; SNK test; vitamin C

\section{INTRODUÇÃO}

O iogurte constitui uma rica fonte de proteínas, cálcio, fósforo, vitaminas e carboidratos. O consumo deste produto está relacionado à imagem positiva de alimento saudável e nutritivo. Esse consumo também pode ser atribuído aos benefícios que o iogurte traz ao organismo humano, tais como: facilitar a ação das proteínas e enzimas digestivas, facilitar a absorção de cálcio, fósforo e ferro, ser fonte de galactose - importante na síntese de tecidos nervosos e cerebrosídeos em crianças, além de ser uma forma indireta de se ingerir o leite (FERREIRA et al., 2001).

$\mathrm{O}$ iogurte é provavelmente o leite fermentado mais popular e de maior importância econômica. É o produto resultante da fermentação do leite pasteurizado ou esterilizado, realizada com cultivos proto-simbióticos de Lactobacillus bulgaricus e Streptococcus salivarius subsp. thermophilus (BRASIL, 2007). Nos últimos 20 anos, a fabricação de iogurte no Brasil cresceu de maneira considerável, registrando uma produção média de 400 mil toneladas por ano, o que representa $76 \%$ do total de produtos lácteos. E dentro deste contexto, verifica-se que a produção 
de iogurte diet vem crescendo de forma exponencial, ocupando importante fatia do mercado (SANTANA et al., 2006).

As frutas são as principais fontes de vitaminas, minerais e fibras que podem ser adicionadas no iogurte na forma de xarope ou em pedaços como uma maneira de sanar perdas de componentes durante a elaboração do produto, além de acrescentar aroma e sabor característico (BRAGA et al., 2012).

Entre os inúmeros frutos do cerrado, a mangaba (Hancornia speciosa) constituem uma fonte de compostos com propriedades funcionais benéficas à saúde, o que pode estimular seu uso pela indústria farmacêutica e de alimentos para o desenvolvimento de novos produtos, promovendo o desenvolvimento sustentável das regiões com as características do cerrado (SIQUEIRA et al., 2013).

Assim, objetivou-se com o presente estudo o desenvolvimento de iogurte sabor mangaba convencional e diet e sua avaliação física e química, para atender também as necessidade de pessoas com restrições alimentares.

\section{MATERIAL E MÉTODOS}

\section{Desenvolvimento do iogurte}

O processamento dos iogurtes foi realizado no Laboratório de Análise de Alimentos do Instituto Federal Goiano - Câmpus Morrinhos. O iogurte foi elaborado adicionando 3\% da cultura láctica ativa, com leite pré-aquecidos a temperatura de $42^{\circ} \mathrm{C}$, posteriormente, submeteu-se a incubação em estufa $\left(42^{\circ} \mathrm{C} / 4 \mathrm{~h}\right)$, até atingir o percentual de acidez desejado $(0,8-0,9 \%$ de ácido láctico). Para cessar a fermentação realizou-se o resfriamento com banho de gelo. Para o iogurte convencional e diet foram adicionado $20 \%$ de polpa da mangaba e $10 \%$ de açúcar para o convencional e $5 \%$ de adoçante culinário para o diet. $O$ produto foi resfriado a 4 으 por 24 horas para sua completa maturação.

\section{Análises Física e Químicas}

As amostras de iogurte convencional e diet de mangaba foram sujeitas às análises físicas e químicas de: $\mathrm{pH}$, acidez titulável (\%de ácido lático) umidade, SST (sólidos solúveis totais), densidade, cinzas e vitamina C seguindo a metodologia do Instituto Adolf Lutz (2004) e o teor de fenólicos totais de acordo Swain e Hills (1959).

\section{Análise estatística}

Para a análise estatística foi aplicada a ANOVA e o teste de SNK (Student Newman-Keuls), nível de significância de 5\%.

\section{RESULTADOS E DISCUSSÃO}

A mangaba apresentou elevado teor de umidade $(79,81)$ próximo ao encontrado por Silva

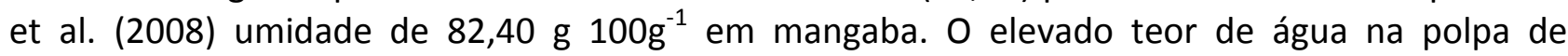
mangaba, juntamente com a fragilidade da casca, torna esses frutos altamente susceptíveis à deterioração enzimática e microbiana, o que dificulta sua conservação.

O teor de cinzas foi inferior ao encontrado por Silva et al. (2008), isso pode ter ocorrido devido o fruto ter sido congelado e ser a polpa integral. O valor encontrado de 4,51 para o pH da polpa da mangaba contradiz com os resultados de Cohen e Sano (2010) pois segundo os autores, a mangaba apresenta um $\mathrm{pH}$ inferior a 4,0. $\mathrm{O}$ fruto da mangaba pode ser considerado como uma fonte de vitamina $C(4,86 \mathrm{mg} / 100 \mathrm{~g})$ quando comparado com outros frutos do Cerrado, como mostrado por Cardoso (2011) no araticum (3,23 mg/100 g) e jatobá (2,91 mg/100 g). 
Tabela 1. Parâmetros físico-químicos médios do fruto de mangaba.

\begin{tabular}{ll}
\hline Parâmetros físico-químicos & Mangaba \\
\hline $\mathrm{pH}$ & $3,73 \pm 0,026$ \\
Acidez titulável (\% de ác. citríco) & $2,39 \pm 0,46$ \\
Sólidos solúveis(o Brix) & $16,33 \pm 0,44$ \\
Cinzas(\%) & $0,44 \pm 0,29$ \\
Umidade(\%b.u) & $79,81 \pm 0,39$ \\
Fenólicos totais(mg de AGE/100mg) & $117,72 \pm 0,48$ \\
Vitamina C & $4,86 \pm 1,18$ \\
\hline
\end{tabular}

Os resultados dos parâmetros avaliados na Tabela 2 do iogurte de mangaba convencional e diet foram obtidos a partir da média de três repetições.

Pode-se observar que os teores de $\mathrm{pH}$, vitamina $\mathrm{C}$ e densidade não teve diferença significativa entre os iogurtes de mangaba convencional e diet. Entretanto, os teores de umidade, SST, cinzas, acidez e fenólicos apresentaram diferenças significativas pelo teste de SNK a 5\%.

Tabela 2. Parâmetros físico-químicos do iogurte de mangaba convencional e diet.

\begin{tabular}{|c|c|c|}
\hline Parâmetros físico-químicos & Convencional $^{1}$ & Diet $^{1}$ \\
\hline $\mathrm{pH}$ & $4,51 \pm 0,03^{*}$ & $4,73 \pm 0,02 *$ \\
\hline Umidade(\%bu) & $66,98 \pm 0,02^{* *}$ & $69,79 \pm 0,52 *$ \\
\hline SST( ㅇ Brix) & $17,5 \pm 0,50 *$ & $10 \pm 0,00 * *$ \\
\hline Cinzas (\%) & $0,755 \pm 0,08^{* *}$ & $1,065 \pm 0,13^{*}$ \\
\hline Acidez látical & $0,625 \pm 0,009 * *$ & $0,906 \pm 0,036^{*}$ \\
\hline Vitamina $C\left(m g 100 g^{-1}\right)$ & $0,704 \pm 0,00^{*}$ & $0,704 \pm 0,00 *$ \\
\hline Fenólicos(mg de AGE/100mg) & $0,750 \pm 0,04^{* *}$ & $0,98 \pm 0,02 *$ \\
\hline Densidade $\left(\mathrm{g} / \mathrm{cm}^{3}\right)$ & $0,99 \pm 0,03 *$ & $1,00 \pm 0,02 *$ \\
\hline
\end{tabular}

${ }^{1}$ Média \pm desvio padrão; ${ }^{*}$ Não apresenta diferença estatística pelo teste SNK (nível de $5 \%$ de significância), ${ }^{* *}$ apresenta diferença estatística pelo teste SNK (nível de $5 \%$ de significância).

Conforme se observa na Tabela 1, o pH no iogurte convencional foi de 4,51, e no diet de 4,73 , ficando acima do encontrado para o iogurte caseiro de 4,03, segundo por Silva et al. (2011), porém a variação pode ter ocorrido devido o iogurte estudado ser saborizado. $\mathrm{O}$ pH é importante, uma vez que o iogurte com baixa acidez $(\mathrm{pH}>4,6)$ favorece a separação do soro, porque o gel não foi suficientemente formado, por outro lado, em pH $<4,0$ ocorre a contração do coágulo devido à redução da hidratação das proteínas, ocasionando também o dessoramento do produto (SILVA et al., 2011)

A umidade entre os iogurte convencional e diet variou de 66,98 a 69,79, respectivamente, embora não tenha valores na legislação para este produto.

O teor de sólidos solúveis teve diferença significativa entre o iogurte convencional e diet, o que já era esperando devido o teor de sólidos ser superior no açúcar.

Pode-se observar que o teor de vitamina $C$, não teve variação entre os iogurte convencional e diet, porém houve um decréscimo comparado a polpa de mangaba, isso pode ter ocorrido devido vários fatores e principalmente devido a pasteurização que degrada a vitamina C.

Os compostos fenólicos encontrados nos iogurte foi inferior a $1 \%$ do encontrado na polpa in natura, tal fato indica a influência de possíveis diferenças de processamento (tipo e tempo de extração, tratamento térmico, tratamento enzimático etc) entre os iogurte estudado (MALACRIDA; MOTTA, 2005).

O percentual de acidez encontra-se dentro da legislação para leites fermentados, que prevê valores entre 0,60 e 2,00\% de ácido lático, e os valores encontrados ficaram na faixa de 
0,625 a 0,906\% de ácido lático, a variação também foi encontrada por Granada et al.(2005) para a acidez na geleia de abacaxi light e a convencional.

\section{CONCLUSÕES}

O desenvolvimento de iogurte de mangaba seria uma boa opção para o mercado. Pois o processamento de frutos sazonais e um modo de aproveitamento do fruto o ano todo. A procura por produtos dietéticos vem aumentando a medida com que a população passa a se preocupar mais com a saúde, a restrição alimentar de alguma pessoas ao uso de sacarose impulsiona mais o mercado de produtos diet.

\section{REFERENCIAS}

BRAGA, A. C. C. , ASSIS NETO, E. F., VILHENA, M. J. V. Elaboração e caracterização de iogurtes adicionados de polpa e de xarope de mangostão (Garcinia mangostana L.). Revista Brasileira de Produtos Agroindustriais, v.14, n.1, p.77-84, 2012. https://doi.org/10.15871/15178595/rbpa.v14n1p77-84

BRASIL. Ministério da Agricultura Pecuária e Abastecimento. Regulamento Técnico de COHEN K. O.; SANO, S. M. Parâmetros físico-químicos dos frutos de mangabeira. Embrapa Cerrados, Planatina, DF, 2010.

CARDOSO, L. M. Araticum, cagaita, jatobá, mangaba e pequi do cerrado de Minas Gerais: ocorrência e conteúdo de carotenoides e vitaminas. 2011.78f. Tese( Doutorado em Ciencia da Nutrição) Universidade Federal de Viçosa, MG.

FERREIRA, L. L. F. C.; MALTA, H. L.; CARELI, R. T. Verificação da qualidade físico-química e microbiológica de alguns iogurtes vendidos na região de Viçosa. Revista Instituto Laticinio "Cândido Tostes", v.56, n. 321, p.152-158, 2001.

GRANADA, G. G., ZAMBIAZI, R. C.; MENDONÇA, C. R. B.; SILVA, E. Caracterização física, química, microbiológica e sensorial de Geléias light de abacaxi. Ciência Tecnologia de Alimentos, v.25, n.4, p. 629-635, 2005. https://doi.org/10.1590/S0101-20612005000400002

INSTITUTO ADOLFO LUTZ. Métodos físico-químicos para análise de alimentos.4.ed. São Paulo: Instituto Adolfo Lutz, 2004.

MALACRIDA, C. R., MOTTA, S. Compostos fenólicos totais e antocianinas em suco de uva. Ciência Tecnologia de Alimentos, v.25, n.4, p. 659-664, out.-dez. 2005. https://doi.org/10.1590/S0101$\underline{20612005000400006}$

BRASIL. Produção, Identidade e Qualidade de Leites Fermentados. Instrução Normativa no46. Diário Oficial da União, 23 de outubro de 2007. Brasília: Ministério da Agricultura, 2007.

SANTANA, L. R. R., SANTOS, L. C. S., NATALICIO, M. A., MONDRAGON-BERNAL, O. L., ELIAS, E. M., SILVA, C. B. , Leila Q. ZEPKA, L. Q., MARTINS, I. S. L., VERNAZA, M. G., CASTILLO-PIZARRO, C., BOLINI, H. M. A. Perfil Sensorial de logurte Light, Sabor Pêssego. Ciência Tecnologia de Alimentos, v. 26, n.3, p. 619-625, 2006. https://doi.org/10.1590/S0101-20612006000300021

SILVA, M. R. et al. Caracterização química de frutos nativos do cerrado. Ciência Rural. v. 38, p. 1790-1793, 2008. https://doi.org/10.1590/S0103-84782008000600051 
SILVA, M. S. S.; FIGUEIRÊDO, R. M. F.; QUEIROZ, A. J. M.; SANTIAGO, V. M. S. Avaliação físicoquímica e sensorial de doces cremosos produzidos com soro de leite de cabra, leite de vaca e polpa de umbu. Revista Brasileira de Produtos Agroindustriais, v.13, n.Especial, p.397- 410, 2011.

SIQUEIRA, E. M. de A.; ROSA, F. R.; FUSTINONI, A. M.; SANT'ANA, L. P.; ARRUDA, S. F. Brazilian savanna fruits contain higher bioactive compounds content and higher antioxidant activity relative to the conventional red delicious apple. Plos One, v.8, n.8, p.1-7, 2013. https://doi.org/10.1371/journal.pone.0072826

SWAIN, T.; HILLIS, W. E. The phenolic constituents of prunus domestica. The quantitative analysis of phenolic constituents. Journal of the Science of Food and Agriculture, v. 10, p. 63-68, 1959. https://doi.org/10.1002/isfa.2740100110 